\title{
Constraints on and dimensions of military interpreter neutrality
}

\section{Pekka Snellman}

Finnish Defence Forces, Finland

pekka.snellman@mil.fi

Military interpreters are soldiers assigned to interpretation duties. As soldiers, they may approach the notion of interpreter neutrality differently from civilian interpreters. This paper addresses the neutrality of military interpreters and contributes to the discussion on interpreter loyalty. The author's own experiences and interviews with 14 Finnish military interpreters who have served in crisis management operations form the basis of this article. I examine neutrality as an ethical concept in its physical, professional, linguistic and cultural dimensions. Moreover, I explore the relationship between neutrality, loyalty, trust and identity. The results suggest that issues regarding neutrality are more complex for military interpreters than for their civilian counterparts. Furthermore, military interpreters may not always be considered neutral in the sense traditionally attributed to interpreters and with regard to the established ethical guidelines of the profession in particular.

\section{Introduction}

A military interpreter is a soldier who is proficient in one or several foreign languages and cultures who has been assigned to interpretation duties. ${ }^{1}$ Military interpreters undergo military training and usually have a military rank, wear a uniform with military insignia and carry weapons. Their primary duty is to facilitate military operations by interpreting, but they can also be assigned other duties related to language and culture, such as information-gathering, intelligence analysis or training other soldiers in cultural awareness (Snellman, 2014, pp. 9-10). In addition, military interpreters may be required to serve in various types of military environment, situation, and threat level.

Linguistic support is vital to the success of military operations in foreign theatres (cf. Jones \& Askew, 2014). For this reason, the military organisations of several nations recruit, train and deploy their own military interpreters. However, military interpreters constitute only a small minority of all interpreters working in present-day military operations. In fact, most interpreters working for the military in crisis management operations, for example in Afghanistan, have a civilian ${ }^{2}$ status. This does not suggest that civilian or locally employed interpreters are inferior to military interpreters; each category of linguists has their 
individual strengths and weaknesses, and can be deployed accordingly ${ }^{3}$ (cf. Lewis, 2012, pp. 64-65).

A number of studies related to interpreting and the military have been conducted in recent years (e.g., Baker, 2010; Footitt \& Kelly, 2012a, $2012 \mathrm{~b}$ ), but few have focused directly on military interpreters. Instead, the emphasis has predominantly been on locally recruited civilian interpreters who have worked for the military. In contrast, this article addresses questions related to the neutrality of military interpreters and contributes to the discussion on interpreter loyalty by presenting a military viewpoint on the subject. This analysis attempts to determine the dimensions that define the neutrality of military interpreters and whether their neutrality is constrained. In other words, how does the notion of neutrality ${ }^{4}$ differ in the perspectives of military and civilian interpreters? Furthermore, do the professional ethical guidelines established for civilian interpreters also apply to military interpreters? Finally, should military interpreters be issued with a different professional code that specifically stipulates the particularities and limitations of their neutrality? I address these questions through consulting interviews that I have conducted with Finnish military interpreters who have served in crisis-management operations. The theoretical framework used to identify and categorise the relevant information in these interviews is grounded theory. This analysis is based upon my Master of Arts thesis (Snellman, 2014). However, in this article, the analysis of military interpreter neutrality in its different dimensions is developed further.

By definition, military interpreters' duties involve facilitating the objectives of military operations (Lewis, 2012, p. 67). This analysis examines the question of whether military interpreters can be regarded as neutral mediators in the sense traditionally attributed to interpreters. Previous research suggests that, in conflict and war, there is no room for neutrality because everyone is forced to choose sides (e.g., Baker, 2010; Kahane, 2007). It could therefore be argued that the professional stances of civilian and military interpreters are contradictory in relation to neutrality, as military interpreters tend to view themselves primarily as soldiers rather than as interpreters (cf. Kelly, 2012, p. 238; Kelly \& Baker, 2013, p. 42; Probirskaja, 2016; Snellman, 2014, p. 54). However, the notion of neutrality in this article is not limited to attributes of professionalism, as neutrality may be described in various terms when observed from a cultural, physical or linguistic perspective. Moreover, I argue that the concept of neutrality is in itself complex and highly subjective, and that loyalty, ${ }^{5}$ trust, identity and neutrality are all facets of the same phenomenon. Thus, by adopting another perspective, a manifestation of neutrality may be perceived instead as an example of lacking loyalty or trust. 


\section{Research data, analysis methods and conceptualization}

\subsection{Interview data}

In-depth interviews were conducted with 14 Finnish military interpreters who have served in four different Finnish crisis-management operations. The interview data were originally collected in 2012-2013 for the purposes of my Master of Arts thesis (Snellman, 2014). The transcriptions of these semi-structured interviews, more than 350 pages in total, are still available to the author, providing an ample basis for further analysis. ${ }^{6}$ The average duration of the interviews was one hour 24 minutes, with an overall duration of 19 hours 36 minutes. The interviews focus on the military interpreters' agency in the Finnish crisismanagement force. They cover topics such as the recruitment, training, motivation and experiences of military interpreters. While the original interviews were not specifically aimed at addressing questions concerning the neutrality of military interpreters, these questions profoundly affect the agency of military interpreters, and many themes that are relevant to this article were frequently referred to during the interviews.

As mentioned above, the research data in this article have previously been used for another study by the author (Snellman, 2014). This article therefore includes a number of references to the results and conclusions of my previous, more extensive study. By applying the results of my Master's thesis, I aim to supplement and develop the analysis of the data by incorporating similar methods. Nevertheless, the focus of this article differs distinctly from the previous study: Snellman (2014) examines the agency of Finnish military interpreters, of which neutrality is only one aspect. In contrast, this article focuses on the dimensions in which their neutrality is manifested as well as on the constraints on this neutrality.

\subsection{Methods of analysis}

As an object of study, military interpreter neutrality is a phenomenon illustrated in the thoughts and actions of the interviewees. This suggests that military interpreters are agents, that is, individuals who possess agency (cf. Probirskaja, 2016; Snellman, 2014) and who use their agency to think and to act. The military interpreters' thoughts and actions occur in the context of military operations. Hence, they are influenced by both the physical reality and the psychological factors present in military operations. These influences are subsequently reflected in the interpreters' interviews. A detailed analysis of the interviews enables a researcher to approach the phenomenon of military interpreter neutrality 
through the meanings that the interviewees attribute to their own thoughts and actions as well as to the influencing external factors.

However, as a phenomenon and a target for understanding, military interpreter neutrality is positioned with each individual interviewee. It may therefore not be fully understood by an outside researcher. The researcher must therefore approach and analyse the phenomenon hermeneutically through his or her pre-understanding of the subject-matter (Varto, 2005, pp. 18-19, p. 23). Correspondingly, the findings from the interview data are reflected here against my own experiences of service in Afghanistan. ${ }^{7}$ In addition, the focus of this article echoes the Finnish Defence Forces' interest in the subject; a study on the topic of the training of military interpreters and the language policy of the Finnish Defence Forces is ongoing (Snellman, in press).

The analysis of the interview data for this article is based on grounded theory, and it consists of three stages. In the first stage, I searched the interview transcripts for the Finnish equivalents of the keywords of 'neutrality' ('impartiality'), 'loyalty', 'identity' and 'trust'. These keywords were identified in the research framework and the results of my MA thesis (Snellman, 2014, p. 5, p. 96). During the second stage, the keywords were examined in their original context, such as their concurrence with a specific interview question or theme, and a number of classes were identified. The classes were formed according to the topic(s) addressed in each of the interview excerpts in which the keywords occurred. Subsequently, matching and overlapping classes were combined into categories or themes to reduce their number. The second stage also involved removing irrelevant search results, such as interview questions and repetitions. In the third and final stage, the combined categories were identified as primary categories and appropriately named (cf. Strauss \& Corbin, 1990, pp. 96-115, pp. 116-122). These primary categories formed the four dimensions of military interpreter neutrality (see Section 2.3 below).

Next, the excerpts from the interview transcripts that had been identified by keywords were examined in relation to the defined dimensions, depending on which dimensions they addressed. At this stage, the interview excerpts were also tagged with an identification number that was assigned to each interviewee. The tagging was implemented to detect the possible influence of the backgrounds of the individual interviewees, such as their experience in professional interpreting or their military training.

\subsection{Dimensions of neutrality}

To analyse the concept of military interpreter neutrality, I use a framework consisting of four dimensions (see Figure 1 below). These four dimensions provide the context for examining different elements of 
this neutrality. For the purposes of this analysis, the dimensions of military interpreter neutrality are:

- the physical dimension, which consists of the physical and social reality in which military interpreters serve;

- $\quad$ the professional dimension, which comprises the professional ethos of the soldier and the interpreter;

- $\quad$ the linguistic dimension, which consists of the language spaces of a Finnish crisis management force in a multinational crisis management operation (typically with the working languages of Finnish, English and the local language of the operation area), and

- the cultural dimension, which comprises the cultural domains between which military interpreters mediate: Finnish culture, local culture and military culture (or more specifically Finnish military culture).

Given the elusive nature of the concept of neutrality, a more detailed conceptualisation of the different dimensions of neutrality would be justified, particularly in a military context. This is, however, beyond the scope of this analysis. Instead, the dimensions will be outlined in more detail using meanings identified in the research data in Sections 3.1 to 3.4 .

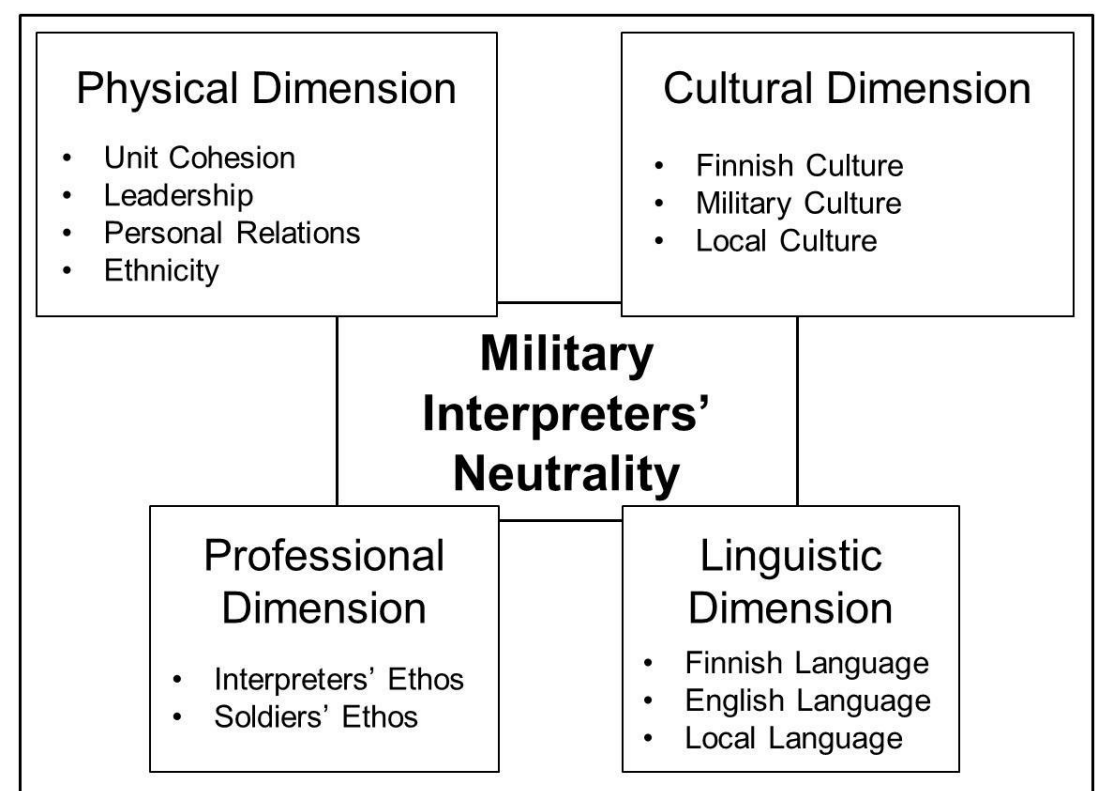

Figure 1: Dimensions of military interpreter neutrality

These dimensions may seem artificial. For example, the cultural and physical dimensions are often inseparable, overlapping and lacking 
clearly defined borders, especially in a military context. For instance, being deployed in the field as a part of a military unit inevitably indicates immersion in military culture. Nevertheless, while this four-dimensional model of analysis does not comprehensively cover the multifaceted concept of neutrality, it aids in highlighting its intricacy. Without a suitable framework of reference, the many aspects of neutrality remain elusive and difficult to identify. This model of analysis, therefore, accentuates the fundamentally ethical nature of questions related to military interpreter neutrality, as addressing and solving these questions presupposes ethical awareness and integrity from the military interpreter (cf. Baker, 2013; Moser-Mercer, 2008).

\subsection{Constraints on neutrality}

Neutrality is a characteristic and a virtue of the interpreting profession (cf. Baker \& Tobia, 2012, p. 220). It is practically always included in the ethical guidelines for interpreters, even in those specifically formulated for interpreters working in conflict zones (cf. AIIC, 2012; FIT, 2009). Kelly and Baker (2013, pp. 155-156) describe the shared belief in the interpreter's commitment to neutrality as a 'short-cut to trust'. For example, professional interpreters must exercise impartiality and confidentiality towards all the parties involved. Nevertheless, the view of the interpreter as an always-neutral actor has been contested. For example, in the context of interpreting for asylum-seekers, interpreters have been found to use their knowledge and professional experience to make strategic choices about whether to adhere to or ignore the ethical guidelines (Inghilleri, 2005, p. 75). Pöllabauer (2004, pp. 174-175) concludes that the interpreters' behaviour with respect to neutrality varies, but their clients often do not regard the interpreters as neutral mediators. Pöllabauer (2004) also concludes that the traditional ethical guidelines for interpreters "may only be valid on paper" (pp. 174-175). Interpreters are human beings who are subject to the influence of personal, social and institutional factors and whose neutrality is shaped in their interactions with their clients (cf. Angelelli, 2004, p. 47; Roy 2000, p. 121).

For military interpreters, the notion of neutrality may be more complex than for civilian interpreters. The idea of neutrality in connection with soldiers, and military interpreters in particular, has been considered problematic (Baker, 2010, pp. 210-211; Kelly \& Baker, 2013, p. 156; Snellman, 2014, pp. 59-61). Baker (2010, p. 200) argues that, in conflict situations, loyalties must not be divided or even strained. Probirskaja (2016, p. 207) extends this idea by stating that "[t]he picture of the neutral, impartial interpreter who simply interprets does not suit the war context in any way". It is important to note that the concept of neutrality 
appears in a different light in the contexts of military versus civilian interpreters (cf. AIIC, 2012).

In the introductory section of this article, I argued that military interpreters primarily regard themselves as and act as soldiers rather than interpreters. This means that their neutrality should be observed in similar terms. For soldiers and the military profession at large, loyalty has been considered a military virtue and an important constituent of unit cohesion (cf. Salo, 2012; Siebold, 2001). Consequently, military interpreters may not always be considered to be neutral in the sense that is expected of their civilian counterparts. Typically, military interpreters are regarded by all parties in a conflict as belonging to, being loyal to and serving one party only - that is, the military organisation in which they serve. Moreover, their fellow soldiers may not always appreciate their efforts to operate in a neutral language space or between cultures (cf. Baker \& Tobia, 2012, p. 202; Kahane, 2007; Snellman, 2014).

To be able to perform their duties, military interpreters must be trusted by their fellow servicemen. The agency of Finnish military interpreters is founded on their trustworthiness or loyalty as perceived by the other members of the crisis-management force (Snellman, 2014, p. 97). It would therefore seem that, within the sphere of influence of a military culture, trust is founded upon loyalty, or 'non-neutrality', rather than on neutrality, which would be the norm in civilian interpreting settings. In contrast, neutrality constitutes a cornerstone of trust for interpreters in civilian environments. Perhaps a more fitting term for neutrality in a civilian context would be impartiality, that is to say, the ability to remain 'non-loyal' to any one party or client ${ }^{8}$. Hence, trusting an interpreter appears to be fundamentally a matter of perspective, as it derives from each client's subjective perception of the impartiality of the interpreter.

The above considerations suggest that, at a conceptual level, neutrality, trust and loyalty ${ }^{9}$ are mutually interwoven and interdependent so that a shift in the position of one must invariably affect the others (see Figure 2 below). Essentially, conceptions of neutrality are subject to the identities of individuals. The context of interpreting involves mediation between two parties, client $\mathrm{A}$ and client $\mathrm{B}$, and the interpreter, who also acts as a third party in the communication. In this context, each party's perceptions of trust, loyalty and identity towards the other parties must be considered separately. This means that trust and loyalty towards one party, or a lack thereof, may be understood by another party as a limitation of the military interpreter's neutrality. In other words, the neutrality of a military interpreter, as perceived by one individual (client A), could contribute to undermining the trust and/or loyalty of the military interpreter in terms of another individual (client B). Moreover, as suggested above, connotations associated with the concepts of neutrality, trust, identity and loyalty are prone to change when examined in a military or a civilian environment. 


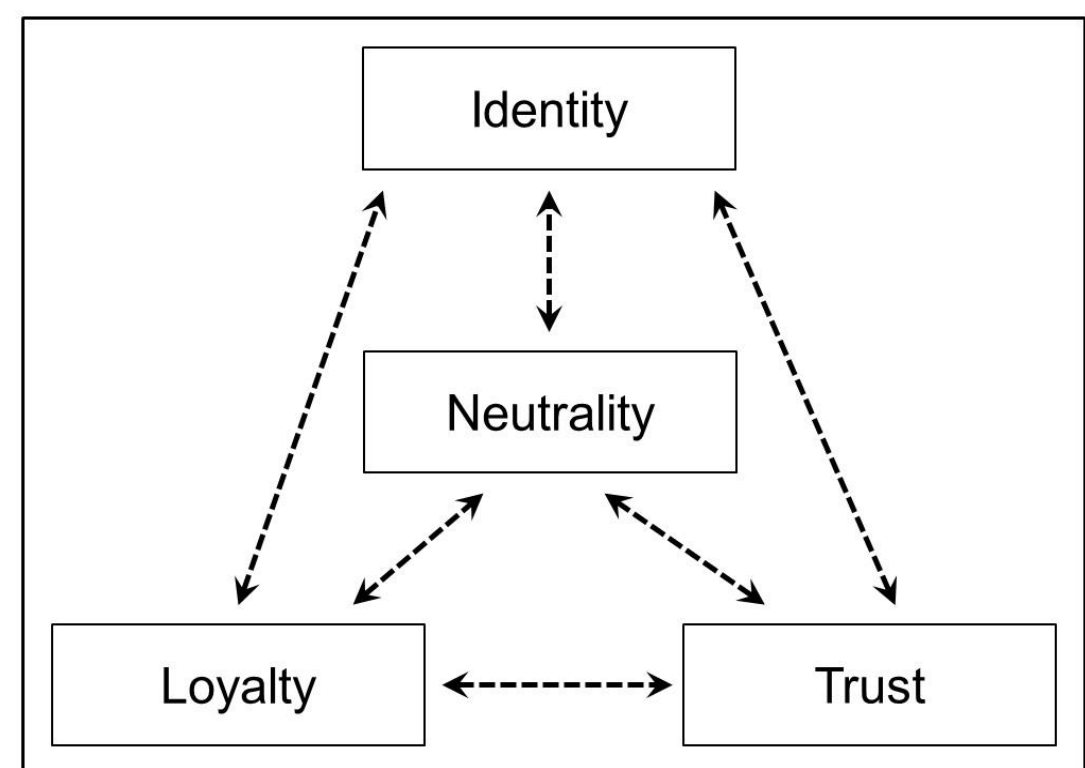

Figure 2: Constraints on military interpreter neutrality. Neutrality is subject to the identity, loyalty and trust of individuals.

\section{Results}

\subsection{The physical dimension of neutrality}

Military interpreters act as part of a military unit. This is the physical dimension of their neutrality, which in this paper also covers any relevant influences from social interaction, such as unit cohesion, personal relations, leadership and ethnicity. Although remaining 'neutral' and detached from any conflict may be a central part of the mission statement of the crisis management force in which they serve, the military interpreters themselves may hardly be considered neutral actors: in the physical dimension, they often perceived themselves to be "just Finnish soldier[s]" (Interview ${ }^{10}$ ) and regarded themselves as a part of a larger whole, serving a greater purpose. The military interpreters expressed a commitment to their unit and its mission in the operation, as well as to Finland and to the Finnish Defence Forces as an institution. This is emphasised by the fact that Finnish citizenship is a requirement for serving as a soldier in a Finnish crisis management force.

The interviewees generally described their interactions with their fellow servicemen and their leaders in very positive terms, and many considered good personal relations with other soldiers of the crisismanagement force to be an important source of motivation. The 
importance of personal relations and group cohesion in military units is a well-known phenomenon. In a study on informal group norms in military units, Harinen (2011) identifies loyalty to the group and to one's peers as well as conforming to group norms as overriding informal norms. The interviews suggest that despite differences between military interpreters and other soldiers in their daily duties and in their ethnic backgrounds and their language identities, these types of informal norm also apply to military interpreters.

That the military interpreters belong to the group is emphasised by their identical external appearance to the other soldiers of the crisis management force, including their clothing, equipment and weapons. The importance of wearing a uniform appeared frequently in connection with questions related to neutrality. This is understandable because a uniform identifies its wearer as a soldier. As one interviewee stated, "[...] the moment you put on a uniform you're no longer neutral" (Interview). Therefore, wearing a Finnish military uniform with national emblems affirmed the military's trust and, in a wider sense, the Finnish nation's trust in the military interpreters (cf. Baker, 2013, p. 158). Wearing a military uniform and carrying a weapon conveys a message of ultimate trust (Jones \& Askew, 2014, p. 179). Furthermore, the locals felt that the uniform effectively deprived the military interpreters of their neutrality; it positioned them not only as soldiers but also as an authority with considerable power and influence (Snellman, 2014, p. 47, p. 64).

One of the interviewees had worked as a local interpreter for the Finnish crisis-management force prior to being granted Finnish citizenship and applying for the position of a military interpreter. According to this interviewee, the position of a locally recruited civilian interpreter differs considerably from that of a military interpreter, and this also applies to neutrality:

Everything changed. First, the understanding of what we're doing there. And then [...] of course the status as an interpreter, it's completely different for a military interpreter than for a local interpreter. [...] There's quite a difference, let's put it that way. Then you are one of them, when you are wearing a uniform there. That is the difference. And for a good reason, I must say (Interview).

The interviewees mentioned only a very limited number of situations where their loyalty had been questioned because of their ethnicity. The interviewees stressed that while they were themselves able to remain neutral in these situations, their agency was undermined by the lack of trust from a few individuals among their fellow soldiers and, in some cases, from the locals. In the words of one interviewee: "[...] sometimes it felt like someone was questioning my neutrality a little. But I didn't care" (Interview). Interestingly, from the military interpreters' perspective, the 
problem does not seem to be the absence of neutrality but rather the absence of loyalty. As one interviewee expressed it, "[...] every military interpreter thinks about whether the others are thinking whether he's loyal or not" (Interview). In other words, the results propose that military interpreters' neutrality in the physical dimension is profoundly constrained.

\subsection{The linguistic dimension of neutrality}

Language is an instrument for shaping the self-image of an individual, as well as for learning the cultural values, norms and world view of his/her own group. Language is, therefore, also associated with the concept of belonging to a certain group. On the other hand, language separates the members of a group from people who do not speak that language (Iskanius, 2006, p. 66). Therefore, language serves a key function in shaping a person's identity (cf. Kelly, 2012, p. 236). Language is a fundamental element, not only of individual identity and self but also of national identity. It structures individual thought as well as the collaborative and collective thought processes of a society (Joseph, 2004). Language and culture are both inherently interrelated to and interdependent on one another.

Language identity denotes the use of a common language, as a language conveys its user's view of the world and thus a sense of togetherness with other users of that language (Iskanius, 2006, p. 64). However, the way in which language is used may change depending on the situation and the recipients. Thus, language users may have multiple language identities. In addition, as the use of language draws boundaries between 'us' and 'them', proficiency in multiple languages enables the user to switch between groups with different language identities (Iskanius, p. 64). The role of language identities is emphasised particularly when the language users are separated from their native linguistic and cultural settings and are faced with an option of using languages other than their mother tongue. It has been claimed that retaining one's native language and switching between languages are intertwined with many psychological and social phenomena (Iskanius, $p$. $61)$.

Similarly, language competence has been perceived as a proxy for neutrality, as well as a source of power in the military hierarchy (cf. Footitt \& Kelly, 2012a, pp. 241-242). I have emphasised the importance of trust for military interpreters earlier in this article. At the linguistic level, the clients' trust in their interpreter is based on the interpreter's skill and competence, that is, on his or her ability to convey the clients' intended message. The military interpreter's greater access to languages and cultures, as well as the position of power that this access enables, may generate asymmetry and distrust between him or her and other 
soldiers (Jones \& Askew, 2014, pp. 176-177). Rafael (2007, p. 242) elaborates on the military's simultaneous dependence on and distrust of interpreters, referring to interpreters as "at once indispensable and troubling" for the military. However, the majority of the interviewed military interpreters, while being fluent in multiple languages, felt that their national identity was decisively Finnish. In the words of one interviewee, "Personally, I didn't see [my ethnicity and understanding of the local language] as a problem. I felt much more like a Finn, after living so many years in Finland" (Interview).

In comparison with the other dimensions of neutrality, the linguistic dimension displays perhaps the fewest differences in neutrality between a civilian and a military interpreting context. The linguistic dimension may be the one dimension in which it is easiest for military interpreters to remain neutral. The interviewees themselves considered that, in general, they had been able to remain neutral in their interpreting duties (Snellman, 2014, p. 58). In the words of one interviewee, "A soldier has orders, yes. That is a conflict of interests, but as I said, you have to learn how to act neutrally while being partial" (Interview).

The common working language of multinational crisismanagement operations is English. However, when only Finnish soldiers are present, Finnish military interpreters have the option of interpreting between Finnish and the local language, that is, the mother tongues of both clients. This would arguably position the military interpreter more neutrally between the clients, as both clients would be using their native languages. However, a far more common situation in multinational operations is that soldiers from multiple nations are present, and that the military interpreter interprets between English and the local language. Although the use of English may not affect or constrain the military interpreter's neutrality, it has been reported to cause difficulties due to the limitations in the English competences of soldiers (cf. Snellman, 2014, p. 21, p. 49; Tiilikka, 2014, p. 52).

\subsection{The cultural dimension of neutrality}

Finnish military interpreters operate simultaneously in three distinct cultural domains: Finnish culture, the local culture of the operation area, and (Finnish) military culture. To mediate competently between these domains, the interpreters need an adequate understanding of all three cultures (cf. Lewis, 2012, pp. 61-62). The interviews suggest that, while an understanding of the local culture of the area is essential to military interpreters in crisis-management operations, fluency in Finnish culture and military culture in particular could be even more valuable. Knowledge of Finnish culture enabled the military interpreters to view matters from a "Finnish perspective", and their military training allowed them to work efficiently as a part of a military unit. Therefore, their 
cultural proficiencies in many ways delineated their agency as military interpreters and consequently determined their position with regard to neutrality. The military interpreters' 'Finnishness' and 'soldiership', as perceived by their comrades in arms, are vital constituents of the trust that enables them to function as members of a Finnish military unit (Snellman, 2014, p. 97).

At the cultural level, the military interpreters' military training and experience gained by serving in a military organisation may be even more crucial than their understanding of national cultures. When recruiting military interpreters, previous military training and experience are considered a merit but not a requirement. The concepts of trust and loyalty are characteristically founded on different attributes in military culture than they are in civilian culture. Loyalty to the Defence Forces is a very strong cultural norm for officers in the Finnish Defence Forces. Loyalty in a military culture infers togetherness, sameness and comradeship. For soldiers, loyalty manifests itself as group cohesion, understood as loyalty to one's close fellow servicemen. Military culture regards clear-cut orders, loyalty and the ability to execute orders as virtues. In contrast, military culture does not value abilities such as argumentation and intellectuality as highly because they do not contribute to social cohesion (Rantapelkonen, 2015, p. 71).

Knowledge of military culture facilitates military interpreters' work in the crisis-management force, particularly with regard to special vocabulary but also by familiarising the military interpreter with the military hierarchy, taking orders and being a part of a bigger unit (Snellman, 2014, pp. 38-39). In addition, Lewis (2012, p. 62) mentions field skills and robustness as basic requirements for military linguists. Basic military training is usually included in the training of military interpreters (Snellman, 2014). Many of the interviewees also emphasise the ability to cope independently in the field and the experience of working with the military in general as helpful qualities in their work as military interpreters.

It is also important to note that when the military interpreters with an immigrant background served in a region closer to their native culture, they became more aware of how well they had assimilated into Finnish culture. While many interviewees indicated "loyalty" or "trustworthiness" as one of the most important qualities of a military interpreter, two interviewees described trustworthiness as a quality of "Finnishness" above all, so that the more Finnish one is, the more trustworthy one is (Snellman, 2014, p. 57). One interesting observation is that when the interviewees mentioned patriotism and altruism as sources of motivation for their service as military interpreters, they were referring to their nation of origin as well as to Finland. In this context, the military interpreters' expressions of loyalty that were divided between the local culture and Finnish culture could be viewed as a burden by the other members of their unit due to the interpreters' immigrant background. Baker and Tobia 
(2012, pp. 202-203) identify these types of divided loyalty as problematic and conclude that it might be unreasonable to demand neutrality from interpreters during and after a war.

Tymoczko (2003, p. 201) notes that questions regarding interpreter loyalty often arise because interpreters are committed to a cultural framework, whether that framework is the source culture, the receptor culture or a third cultural framework. Therefore, interpreters easily risk becoming "the traitor from within or the agent from without" (Tymoczko, 2003, p. 201). Kahane (2007) argues that forcing interpreters to be neutral during conflict imposes an ethical and moral stress on them because no neutral space between cultures and/or languages exists during conflict. Kahane also observes that no party is willing to grant interpreters neutral space to occupy in the context of a conflict and elaborates on the expression "the violence of neutrality" to describe this phenomenon. Moser-Mercer (2008) reports that, in the context of conflict, interpreters often need to assume ad hoc roles that they do not master and that often involve ethical decision-making and may lead to "misplaced loyalties". The interviews suggest that military interpreters, who have clearly defined positions in both the cultural and the physical dimensions, do not need neutral cultural spaces to occupy, nor do they need to shift their roles between cultures.

\subsection{The professional dimension of neutrality}

Both serving as a soldier and working as an interpreter can be considered professions (cf. Inghilleri, 2005; Nokkala, Hanska, \& Häyry, 2015; Tyulenev, 2015). In addition to the many obvious and fundamental differences between these two professions, they also differ from the standpoint of neutrality. Typical characteristics of the soldier's profession include accountability, hierarchy and internal as well as external control (Siebold, 2001, pp. 147-148). Moreover, as noted earlier, loyalty towards the individual's group has strong standing as a military virtue. As a concept, professionalism in general infers a tendency to form cohesive, collegial groups with internal control (cf. Tyulenev, 2015). On the other hand, Inghilleri $(2005$, p. 72 ) notes that the interpreting profession is struggling to define itself "both within the interpreting profession and in its relation to other professional practices" (Inghilleri, 2005, p. 74). Inghilleri (2005) criticises the common assumption that interpreters occupy a neutral space in-between cultural and institutional constraints, and calls the interpreter's position within, not between, social spaces "neither fixed nor neutral" (p. 77, pp. 79-80).

In particular, the inherently neutral stance of professional interpreters has been challenged by questions of allegiance and loyalty when working for the military (Footitt \& Kelly, 2012a, p. 240). Baker and Tobia (2012, p. 202) arrive at a similar conclusion: "While interpreting as 
a profession demands neutrality, the users and employers of language intermediaries in conflict demand loyalty." Baker and Tobia (2012) continue, concluding that "being an interpreter in war and conflict deconstructs this paradigm of neutrality" (p. 220). These quotations propose that military interpreters might not subscribe to the professional ethos of a civilian interpreter.

To what extent do the professional attributes of civilian interpreters apply to their military counterparts? It has already been suggested that the majority of the interviewed military interpreters regarded themselves primarily as soldiers rather than interpreters and that for recruitment, military training and experience were considered merits, while not requirements. However, interpreter training and experience were also considered merits but not requirements. A total of seven out of the 14 interviewees had a background in professional interpreting, including interpreter training, before beginning their service as military interpreters. These interviewees reflected more profoundly on matters concerning interpreter neutrality in general and the differences between neutrality for civilian and military interpreters in particular. One interviewee openly questioned the paradigm of neutrality with respect to military interpreters:

[...] A soldier is on someone's side anyway, and if I am a military interpreter then I am on the side of this person. So a normal interpreter would interpret everything both parties say. A soldier doesn't have to. [...] I didn't have to interpret everything to the clients. But as long as the interpreting and information flowed in our direction there was no problem (Interview).

This echoes Kelly's (2012) observation that "the role of military linguists clearly diverges from the model of the civilian translator or interpreter, which carries duties of neutrality in managing communications between languages" (p. 238). On a similar note, Lewis (2012) states that "the military linguist must also understand that (s)he is a facilitator for his/her employer and, therefore, not only not neutral, but active in pursuing the commander's objectives" (p. 67).

The vast majority of the interviewees were familiar with the ethical guidelines for interpreters. Consequently, they considered it possible that, in certain situations, a conflict of interests might arise between what is required of a soldier and what is required of an interpreter. Perhaps the most substantial ethical issue is that military interpreters are under orders from a military organisation which, in certain situations, may contradict the ethical guidelines for interpreters. One interviewee suggested that should a conflict between military orders and the interpreter's ethical guidelines occur, the right thing to do would be to follow the ethical guidelines. The vast majority, however, were of the opinion that a military interpreter could not achieve neutrality - at least not in the sense that neutrality is understood in a civilian setting - and that the orders of 
the military organisation trumped the interpreters' ethical guidelines. In conflicting or uncertain situations where orders or ethical guidelines did not provide support for decision-making, the majority of the interpreters perceived the safety and security of their own unit as a priority:

You have to really consider what's best for the platoon at all times. That's the idea. As long as you are a part of the organisation, at least that's how I understand it [...]. As long as I'm wearing a uniform, I will act according to what that uniform requires and what I'm committed to, to the best of my ability (Interview).

In addition, in strained situations, the interpreters considered it appropriate to act independently of their clients as mediators to resolve and settle a potentially violent conflict (cf. Baker \& Tobia, 2012, pp. 208-209). A similar issue arises with the principle of interpreter confidentiality, which is without exception included in the guidelines for civilian interpreters. In contrast to civilians, the military interpreters frequently broke confidentiality when potential security threats or attempted corruption arose (Snellman, 2014, p. 55). It should be noted in this context that the research data are not conclusive regarding the military interpreters as a professional group, as the interviewees' professional backgrounds were heterogeneous in many respects.

\section{Discussion}

Toiskallio (2005) defines a person's ethos as his or her "habits, socially shared values, rules, and modes of behavior" (p. 135). In a group of people, ethos refers to the collective identity of a social group or a culture. The results of the interviews suggest that, as a group, military interpreters align more closely with the professional ethos of soldiers than with that of interpreters. This is consistent with the military interpreters' formal position as soldiers in a military organisation. As a result, military interpreters do not assume a neutral stance when performing their duties. Furthermore, the results indicate that their position of non-neutrality would cover, to some extent, their interpreting duties, even though a number of interviewees stated that they were able to remain neutral when interpreting. Although the majority of the military interpreters considered it important or even indispensable from an ethical viewpoint to strive towards neutrality, they found it difficult or even impossible for military interpreters to act neutrally in reality. Many admitted that it was simply not possible for military interpreters to maintain their neutrality at a level equal to that of their civilian counterparts. In the words of one interviewee who had worked as a community interpreter in Finland, "If you think about how I have remained neutral here in Finland, you 
couldn't down there. I have to say that you couldn't, and I'm not lying" (Interview).

These different interpretations of neutrality depend on the observer's point of view. An action that, to an outside observer, would appear as partiality or non-neutrality may well appear neutral to military interpreters, as they act within the physical, cultural and professional dimensions of their unit, identify themselves as soldiers and align with the soldier's ethos. One interviewee concluded the following:

Q: Were you, in your opinion, able to remain neutral as a military interpreter?

A: Sure. I was working for the Finns. [...] I was working for the organisation, and I am partial toward the organisation, really. I tried to follow instructions given to me by my superior (Interview).

The interviewer's question regarding neutrality may simply have been misunderstood as referring to loyalty. It is highly probable, however, that the interviewee's ethos or identity as a military interpreter - in other words, as a soldier - predominates over that of an interpreter. It is important to take into account that the above quotation is from a person with military training and experience, but no interpreter training and no professional experience in interpreting. In contrast, an interviewee with seven years' experience of professional interpreting stated the following: "An interpreter is not there to take sides for anyone. When an interpreter starts to go down that path, he's lost the essence of the task" (Interview). Thus, we can see that being loyal to the locals would be difficult for a military interpreter. It is interesting to note that at the same time when the universal demand for neutrality placed on interpreters by definition constrains their opportunities consciously to help the locals (cf. Snellman, 2014 , pp. 44-45), the military interpreters' loyalty to the military works in the same direction.

Identity, loyalty, trust and neutrality can be understood as elements of interpreters' agency, that is, their willingness and ability to act. A central characteristic of agency is that it manifests itself in social interaction with other individuals, cultures, organisations, and so forth (Koskinen \& Kinnunen, 2010, pp. 6-7). In the case of military interpreters, the aforementioned individuals, culture, and organisation would constitute their unit. The results of the current analysis similarly propose that, for military interpreters, the notion of neutrality is attributed to its different dimensions in the context of a military unit. Therefore, in the physical and cultural dimensions, the leeway in terms of neutrality would be very limited, as the military interpreters' perceived neutrality could be understood as insufficient loyalty and trust towards their fellow soldiers.

However, there could be a wider margin for the military interpreters to act neutrally in the professional and linguistic dimensions, 
depending on the positioning of their professional and linguistic identity. This is contested by Baker (2010, pp. 209-213), who argues that in war zones, interpreters' personal sense of identity is overridden and redefined to align with the different ethnicities, militaries, organisations and other parties of the conflict. In contrast, Baker and Tobia (2012) claim that "loyalty, whether divided or shared, does not necessarily need to be the opposite of neutrality" (p. 220). It should be noted that these observations were gathered primarily from data on civilian interpreters employed by the military. Although both views may be well founded, questions regarding neutrality may simply be considered unimportant in military organisations and cultures. Fundamentally, the military is often more concerned with security and trust (cf. Baker, 2013, p. 131; Footitt \& Kelly, 2012a, p. 227; Siebold, 2001).

Nonetheless, military interpreters' apparent partiality or nonneutrality as such should not be perceived as a negative or unacceptable attribute. The findings in this paper indicate that civilian and military interpreters differ in their sense of neutrality. These differences also appear to be largely constructed outside the military interpreters' agency and independently of their actions. Thus, as issues regarding military interpreter neutrality seem to be inclusive and enduring, they should not be criticised but rather studied and embraced as an integral part of the context of conflict, war and the military (cf. Footitt \& Kelly, 2012a, pp. 243-245).

\section{Conclusion}

In crisis-management operations in foreign theatres, the military is often entirely dependent on interpreters, whether it wants to be or not. This being the case, if a military organisation aims to achieve the objectives of an operation, it has no alternative but to trust the interpreters who are available. Failing to build mutual trust between the military organisation and the interpreters that it employs will inevitably result in difficulties, as a lack of trust complicates and hinders the co-operation with interpreters at many levels. In short, a lack of trust severely diminishes the additional value that interpreters provide (cf. Snellman, 2014, pp. 95-97).

It is fair to presume that no one expects military interpreters serving in the Finnish Defence Forces to be neutral in a crisismanagement operation. The parties at the sending and receiving ends of the mediation performed by the interpreter, that is, the members of the military organisation and the locals, usually do not expect neutrality from military interpreters. One reason for this could be that both the locals and the military personnel are often unaware of the interpreter's role and their ability to influence communication (cf. Baker, 2010, p. 214). From the locals' point of view, while military interpreters are non-neutral actors, at least the interpreters' loyalty is fixed to a definite point of reference, that 
is, the military unit in which they serve. From the military organisation's point of view on the other hand, doubts regarding loyalty may lead to a lack of trust, which is indispensable for interpreters. Moreover, the results of this analysis indicate that from the perspective of all the parties involved in mediation, uniform-wearing military interpreters have unquestionably chosen their allegiance. Accordingly, military interpreter loyalty would have fairly little chance of becoming uncertain, misplaced or fluctuating, even in the direst circumstances of a conflict. It is not difficult to imagine crisis scenarios where a fixed allegiance would be an ethical advantage for a military interpreter over the more elusive and multifaceted position of neutrality.

This article has suggested that the clients of military interpreters do not necessarily regard the interpreters as neutral, and that military interpreters have limited space within the different dimensions of neutrality. But does this imply that military interpreters are willing to be excluded from the paradigm of neutrality which is so integral to the interpreting profession? As these problems are profound and ethical in nature, they cannot be solved solely by individual military interpreters. This paper suggests that the existing ethical guidelines for interpreters do not adequately cover all aspects, dimensions and constraints of military interpreter neutrality. New or adjusted ethical guidelines are therefore needed for military interpreters. The established civilian guidelines are a recognised and firm foundation for ethical considerations, but their explicit and unquestionable demand for neutrality may be confusing and misleading in settings of crisis and war. A set of professional ethical guidelines for military interpreters should be formulated in an attempt to define the limits of their neutrality and to specify the dimensions within which neutrality should be striven for.

This is not to say that neutrality in the case of military interpreters needs to be discarded. On the contrary, although their neutrality may be constrained, it must remain a guiding principle in all the mediation they undertake. Military interpreters must always be loyal to the military in order to maintain trust, but they should act neutrally wherever possible. As one interviewee aptly remarked on the qualities of a good military interpreter, "[As a military interpreter,] you have to know the language well, be able to keep calm, and, as I said earlier, be impartial - up to a certain point" (Interview).

\section{References}

AIIC (International Association of Conference Interpreters). (2012). Conflict zone field guide for civilian translators/interpreters and users of their services. The International Association of Conference Interpreters, Red $\mathrm{T}$, and The International Federation of Translators. Version 3/2012. Retrieved from http://red-t.org/documents/T-I_Field_Guide_2012.pdf. 
Angelelli, C. (2004). Revisiting the interpreter's role: A study of conference, court, and medical interpreters in Canada, Mexico, and the United States. Amsterdam: John Benjamins.

Baker, C. (2013). Nationality, ethnicity and trust. In M. Kelly \& C. Baker (Eds.), Interpreting the peace: Peace operations, conflict and language in BosniaHerzegovina (pp. 130-160). Basingstoke: Palgrave Macmillan.

Baker, C., \& Tobia, S. (2012). Being an interpreter in conflict. In H. Footitt \& M. Kelly (Eds.), Languages at war: Policies and practices of language contacts in conflict (pp. 201-221). Basingstoke: Palgrave Macmillan.

Baker, M. (2010). Interpreters and translators in the war zone: Narrated and narrators. The Translator, 16(2), 197-222.

FIT (International Federation of Translators). (2009). Code of professional practice. Regional Centre of the International Federation of Translators. Retrieved from $\mathrm{http} / / /$ www.fit-europe.org/vault/deont/CODE_PROF_PRACTICE.pdf

Footitt, H., \& Kelly, M. (Eds.). (2012a). Languages at war: Policies and practices of language contacts in conflict. Basingstoke: Palgrave Macmillan.

Footitt, H., \& Kelly, M. (Eds.). (2012b). Languages and the military: Alliances, occupation and peace building. Basingstoke: Palgrave Macmillan.

Harinen, O. (2011). Some empirical research results on Finnish soldiers' behavior, group cohesion and informal norms: Three military sociological articles. National Defence University, Department of Behavioural Sciences, 1(1). Retrieved from http://urn.fi/URN:NBN:fi-fe201201241173

Interview. (2012/2013). Interviews with 14 Finnish military interpreters. 20 December 2012-19 April 2013. Interviews conducted by permission and the terms and conditions of the Finnish Defence Command (AI16134, 24 August 2012). The individual interviewees are not identifiable. Material in possession of the author.

Inghilleri, M. (2005) Mediating zones of uncertainty. The Translator, 11(1), 69-85.

Iskanius, S. (2006). Venäjänkielisten maahanmuuttajaopiskelijoiden kieli-identiteetti [Language and identity of Russian-speaking students in Finland] (Doctoral dissertation). University of Jyväskylä. Retrieved from https://jyx.jyu.fi/dspace/handle/123456789/13433

Jones, I., \& Askew, L. (2014). Meeting the language challenges of NATO operations: Policy, practice and professionalization. Basingstoke: Palgrave Macmillan.

Joseph, J. (2004). Language and identity: National, ethnic, and religious. New York, NY: Palgrave Macmillan.

Kahane, E. (2007). Interpreters in conflict zones: The limits of neutrality. Communicate! AIIC Webzine. Retrieved from http://aiic.net/page/2691/interpreters-in-conflict-zones-the-limits-of-neutrality

Kelly, M., \& Baker, C. (Eds.). (2013). Interpreting the peace: Peace operations, conflict and language in Bosnia-Herzegovina. Basingstoke: Palgrave Macmillan.

Kelly, M. (2012). Conclusion: Communication, identity and representation through languages in war. In H. Footitt \& M. Kelly (Eds.), Languages and the military: Alliances, occupation and peace building (pp. 236-243). Basingstoke: Palgrave Macmillan. 
Koskinen, K., \& Kinnunen, T. (2010). Introduction. In T. Kinnunen \& K. Koskinen (Eds.), Translators' agency (pp. 4-10). Tampere Studies in Language, Translation and Culture. Series B 4. Tampere: Tampere University Press. Retrieved from http://urn.fi/urn:isbn:978-951-44-8082-9

Lewis, J. (2012). Languages at war: A UK Ministry of Defence perspective. In H. Footitt \& M. Kelly (Eds.), Languages and the military: Alliances, occupation and peace building (pp. 58-69). Basingstoke: Palgrave Macmillan.

Moser-Mercer, B. (2008). Interpreting in zones of crisis and war. Communicate! AIIC Webzine. Retrieved from http://aiic.net/page/2979/interpreting-in-zones-ofcrisis-and-war/

Nokkala, A., Hanska J., \& Häyry M. (Eds.). (2015). An officer and an academic: Tensions between science, research, and leadership in Finnish defence management. National Defence University, Department of Leadership and Military Pedagogy, 2(15). Retrieved from http://urn.fi/URN:ISBN:978-95125-2662-8

Nord, C. (1989). Loyalität statt Treue: Vorschläge $\mathrm{zu}$ einer funktionalen Übersetzungstypologie. Lebende Sprachen, 34, 100-105.

Pöllabauer, S. (2004). Interpreting in asylum hearings: Issues of role, responsibility and power. Interpreting, 6(2), 143-180.

Probirskaja, S. (2016). Between ideology and ethnicity: Soviet intermediaries in military conflicts between the Soviet Union and Finland. In D. Andres, J. Richter \& L. Schippel (Eds.), Translation und "Drittes Reich": Menschen - Entscheidungen - Folgen. Frank \& Timme, 199-220.

Rafael, V. (2007). Translation in wartime. Public Culture, 19(2), 239-246.

Rantapelkonen, J. (2015). Akateemisen ja sotilaallisen kulttuurin yhdistyminen: Jännitteestä tietämisen paradokseihin [The Convergence of Academic and Military Culture: From Tensions to Paradoxes of Knowing]. In A. Nokkala, J. Hanska, \& M. Häyry (Eds.), An officer and an academic: Tensions between science, research, and leadership in Finnish defence management (pp. 6786). National Defence University, Department of Leadership and Military Pedagogy, Publication Series, 2(15). Retrieved from. http://urn.fi/URN:ISBN:978-951-25-2662-8

Roy, C. B. (2000). Interpreting as a discourse process. Oxford: Oxford University Press.

Salo, M. (2012). Unit cohesion: Theoretical implications and practical recommendations. In M. Salo \& R. Sinkko (Eds.), The science of unit cohesion: Its characteristics and impacts. Department of Behavioural Sciences, Publication Series 1, No. 1/2012, Finnish National Defence University \& Military Sociological Society of Finland, 95-107. Retrieved from http://urn.fi/URN:ISBN:978-951-25-2311-5

Siebold, G. R. (2001). Core issues and theory in military sociology. Journal of Political and Military Sociology, 29, 140-159.

SKTL (The Finnish Association of Translators and Interpreters) (2015). Code of ethics for community and court interpreters. The Finnish Association of Translators and Interpreters. Retrieved from http://sktl-fi- 
bin.directo.fi/@Bin/67b803fd410e6127550862295c378c8f/1462285874/appli cation/pdf/965581/A\%20professional\%20community\%20interpreter\%20adher es $\% 20$ to $\% 20$ a $\% 20$ code $\% 20$ of $\% 20$ ethics-.pdf

Snellman, P. (2014). The agency of military interpreters in Finnish crisis management operations. (Master's thesis). Retrieve from http://urn.fi/URN:NBN:fi:uta201403061187

Snellman, P. (in press). Language Policy, Translation Culture, and Interpreter Tactics in the Finnish Defence Forces. General Staff Officer Course Thesis. National Defence University, Helsinki.

Strauss, A., \& Corbin, J. (1990). Basics of qualitative research. Newbury Park, CA: SAGE.

Tiilikka, J. (2014). Kriisinhallintatehtävissä palvelevien suomalaisten upseerien kielitaito [Language Skills of Finnish Officers Serving in Crisis Management Operations]. Senior Staff Officer Course Thesis. National Defence University, Helsinki. Retrieved from http://urn.fi/URN:NBN:fi-fe2014070132024

Toiskallio, J. (2005). Military ethics and action competence. In E. R. Micewski \& D. Pfarr (Eds.), Civil-military aspects of military ethics (Volume 2): (Military) Leadership and responsibility in the postmodern age (pp. 132-143). Institute for Human and Social Sciences, Austrian National Defense Academy, Vienna. Retrieved from http://www.bundesheer.at/pdf_pool/publikationen/10_cma_12_mea.pdf

Tymoczko, M. (2003). Ideology and the position of the translator: In what sense is a translator 'in between'? In M. Calzada-Perez (Ed.), Apropos of ideology (pp. 181-201). Manchester: St. Jerome.

Tyulenev S. (2015). Towards theorising translation as an occupation. Asia Pacific Translation and Intercultural Studies, 2(1), 15-29.

Varto, J. (2005). Laadullisen tutkimuksen metodologia [Methodology of Qualitative Research]. Retrieved from http://arted.uiah.fi/synnyt/kirjat/ varto_laadullisen_tutkimuksen_metodologia.pdf

1 In association with military linguists, the notion of 'proficiency' is often applied differently than in a civilian context (cf. Lewis, 2012, p. 61). Furthermore, the label of 'military interpreter' does not necessarily denote a professional status or position. If a soldier is ordered to interpret within his/her competence, he/she can be considered a military interpreter.

2 In reference to interpreters' working environment, the terms 'civilian' and 'military' are broadly applied in this paper. A 'civilian' working environment indicates the absence of conflict and threat and a more professionally oriented interpreter-client relationship. A 'military' working environment indicates instead a more stressful environment and a closer- 
knit and more permanent relationship between the client(s) and the interpreter. Moreover, the latter also suggests the presence and influence of military culture. These categories should not be considered exclusive, as 'civilian' and 'military' working environments may exist within both military and civilian organisations.

3 The terms used to denote a military interpreter vary. Terms such as 'Language and Cultural Advisor (LCA)', 'Language officer', 'uniformed linguist', 'military linguist', 'enlisted interpreter', and 'Military Occupational Specialist (MOS) 09L' effectively imply the same concept. They are, in this paper, all referred to as 'military interpreters'.

4 The concept of neutrality refers in this paper to the attribute of not taking sides in a conflict. Thus, military interpreter neutrality is manifested as an ethical effort or ideal by the military interpreters to remain outside a conflict, despite actually having a side or being a side in the conflict themselves.

5 The concept of loyalty, applied in this paper to military interpreters, does not reflect the concept of translator's loyalty introduced by Nord (1989) and established in translation studies. The military interpreters' loyalty to their unit or client is produced in the physical, cultural, and professional dimensions of neutrality, rather than in a linguistic sphere.

6 Further information on the interviews, such as the availability, validity, and reliability of the data, the background, ethnicity, and recruitment of the interviewees, as well as the interview questionnaire used, is available in Snellman (2014, pp. 26-29, pp. 34-35; Appendix A).

7 The author served in the International Security Assistance Force (ISAF) in Afghanistan from 2009-2010 as the commanding officer of the Provincial Office in Samangan province and worked daily with local and military interpreters in the field.

8 This is illustrated in that the ethical guidelines for professional interpreters prefer the term 'impartial[ity]' over the term 'neutral[ity]' (cf. AIIC, 2012; FIT, 2009; SKTL, 2015).

9 The concepts neutrality, trust, and loyalty have existed in the realm of philosophy and must be addressed in such terms for a full understanding of what they mean.

10 All direct quotations from the interviews are translated from Finnish into English by the author. The individual interviewees are not identifiable. 